\title{
Important areas for the conservation of the European Roller Coracias garrulus during the non-breeding season in southern Africa
}

\author{
JUAN RODRÍGUEZ-RUIZ, FRANÇOIS MOUGEOT, DESEADA PAREJO, \\ JAVIER DE LA PUENTE, ANA BERMEJO and JESÚS M. AVILÉS
}

\section{Summary}

The identification of threats to migratory species of conservation concern and the relevance of protected areas for them is often biased towards breeding areas. The European Roller Coracias garrulus is a long-distance migrant experiencing a pronounced decline throughout its breeding range, which has been attributed to the degradation of open agricultural habitats. However, its conservation status in non-breeding areas in Africa remains unstudied. Land cover change is a major threat affecting migratory birds in their wintering grounds, therefore identifying important areas for their protection at this stage is a priority. Here we used occurrence data during the wintering season and ecological niche models to identify key land cover and areas used by Rollers in Africa. First, we used 33 filtered locations from six satellite-tracked birds breeding in Spain to describe suitable wintering areas for the Spanish population (westernmost part of the Eurasian breeding range). We also used 1,167 occurrence data in southern Africa from open-access databases and bird atlases to characterise the overall wintering range of the species. The Spanish population occupied a relatively small area in the north-western part of southern Africa, and a narrow range of land covers. Open grassland, less steep areas and those with sparse tree cover are correlated with suitability. In all, $18.06 \%$ of suitable wintering areas for the Spanish population overlapped with protected areas. The overall population of Rollers occupied a wider area and range of land cover. Tree cover was the most important variable affecting suitability, with areas without tree cover being the least suitable. We found that $9.58 \%$ of suitable wintering areas for the overall population overlapped with protected areas. Our results suggest that Rollers from different origins (breeding populations) use separate, but overlapping, wintering areas and may have different habitat requirements, and therefore, population-specific conservation strategies in these areas might be needed to fully protect the species.

\section{Introduction}

Afro-Palearctic long-distance migrant birds are declining faster than sedentary birds with which they share breeding habitats (Vickery et al. 2014). One possible explanation for this differential decline may be the particular conditions that affect migrants in their wintering grounds and/or in their passage areas (Sanderson et al. 2006). In long-distance migratory birds, mortality rates can be considerably higher during migration than during sedentary periods (Sillett and Holmes 2002, Terraube et al. 2012, Klaassen et al. 2014) and reproductive success can be influenced by the quality of habitats located thousands of kilometres away in their non-breeding grounds (e.g. Norris et al. 2004). Moreover, due to their dependency on disjointed areas that they are likely subjected to diverse conservation policies, migrant birds usually found less protection during their annual cycle 
compared with resident species (Runge et al. 2015). It is therefore critical to improve our knowledge of the ecology, distribution and habitat use of migratory birds outside their breeding season in order to elaborate effective holistic conservation programs (Martin et al. 2007).

In recent decades, breeding populations of the European Roller Coracias garrulus (hereafter, Roller) have suffered among the most drastic declines for Afro-Palearctic migrant farmland birds wintering in open savannas (Sanderson et al. 2006). The annual cycle of Rollers is distributed across their breeding grounds (April-August), non-breeding grounds (November-February) and migratory pathways (August-November for autumn migration and February-April for spring migration) (Rodríguez-Ruiz et al. 2014, Finch et al. 2015). In several countries in Europe, covering most of the global breeding range, the species has become extinct or is declining (Burfield and Van Bommel 2004, Kovacs et al. 2008). The rate of global population decline of Rollers has lessened but not stopped in the last decade, and its conservation status changed recently from 'Near Threatened' to 'Least Concern' (Burfield and Van Bommel 2004, Kovacs et al. 2008, BirdLife International 2015). The reasons for the decline and fragmentation of breeding populations include the loss of suitable habitats, agricultural intensification and misuse of pesticides in breeding areas (Avilés and Parejo 2004, Kovacs et al. 2008). However, there is still an important lack of information on the threats faced by Rollers during migration and on their non-breeding grounds, impeding us from quantifying the relative importance of the different threats year-round.

Recently, the use of geolocators and satellite telemetry has allowed locating the non-breeding grounds of Rollers from the westernmost part of the Eurasian breeding range (France, Portugal and Spain). Rollers from these breeding populations spend the non-breeding season in an area located in southern Angola, northern and central Namibia and northern Botswana (Emmenegger et al. 2014, Catry et al. 2014, Rodriguez-Ruiz et al. 2014). Rollers breeding in Bulgaria, Cyprus, Latvia and Montenegro, however, spend the non-breeding season farther east, between Botswana, Zambia, Zimbabwe, Tanzania and Kenya (Finch et al. 2015). Bird atlases extend the Roller nonbreeding distribution towards the south, with highest densities in the north-east of South Africa, and exclude the most arid areas in the south-west of Africa (Keith et al. 1988, Herremans et al. 1993). The most south-western part is most likely occupied by the subspecies C. g. semenowi, that breeds from Iraq to north-western China (Cramp 1998). Tracking studies from across Europe reveal that Rollers from different breeding populations use different but overlapping non-breeding areas ("moderate connectivity"; Finch et al. 2015). In such a scenario, it is critical to characterise the habitat use and environmental variables that determine species distribution during the nonbreeding season in order to identify potential threats and deliver effective conservation actions for this species. It is also important to assess to what extent the most suitable non-breeding areas are included within the current network of protected areas (PAs). Land cover change is the major threat affecting loss of biodiversity (Sala et al. 2000) and PAs have been proved as an effective measure to reduce loss of natural land cover (Beresford et al. 2013). Assessing the degree of coverage of protected areas on the wintering grounds of Rollers would help to identify potential gaps in protection and key areas for its conservation.

Here we aim to contribute to the conservation of Rollers by identifying key areas and land cover used by Rollers during winter from two different perspectives: from population-specific to the overall species. For that purpose, we develop two different ecological niche models based on climatic, topographic and habitat variables to identify suitable wintering areas for Rollers in southern Africa: first, using satellite telemetry data obtained from individuals marked during breeding in Spain to determine the extent of potential areas used by the Spanish breeding population (hereafter Spanish population) and, second, using online open-access databases on Roller occurrences as input for the model, to identify the requirements and distribution range for the overall species, including Rollers from different breeding origins across Europe (hereafter overall population). Finally, we use the model outputs to evaluate to what extent the most suitable non-breeding areas and land cover types are included within the current network of PAs in Africa. 


\section{Methods}

\section{Occurrence data from satellite tracking}

We used satellite-tracking occurrence data from six adult birds (four males, one female and one unsexed individual) that were trapped during the 2012 and 2013 breeding seasons in Spain at six different locations (provinces of Badajoz, Ciudad Real, Girona, Granada, Lleida and Madrid). Each tagged bird provided only one wintering period. Birds were equipped with $5 \mathrm{~g}$ solarpowered PTT-10o satellite transmitters (Microwave Telemetry Inc., Columbia, MD, USA) that were fitted with a backpack Teflon harness (Garcelon 1985). The device to body-weight ratio was less than $5 \%$ (Rodríguez-Ruiz et al. 2014).

Satellite transmitters were programmed with an $8 \mathrm{~h} \mathrm{ON}$ I5 h OFF duty cycle. We used only high-quality locations, classified according to their accuracy as LC 3 (up to $250 \mathrm{~m}$ ), 2 (up to $500 \mathrm{~m}$ ) or 1 (up to $1.5 \mathrm{~km}$ ) (Argos 2007) to describe non-breeding areas. The start of the wintering period was defined as the day when the bird stopped displacement for more than 1o days. The end of the wintering period was when the bird moved more than $20 \mathrm{~km}$ in a day with a bearing between NW and NE (see Rodríguez-Ruiz et al. 2014 for more details). We filtered locations to avoid pseudoreplication issues associated with repeated locations of a given individual in the same grid cell; for this, we overlapped a grid of 15 arc-min cell size (roughly $25 \times 25 \mathrm{~km}$ ) and selected one random location per cell, obtaining a total of 33 locations (1-9 locations per bird).

\section{Occurrence data from online databases}

In order to describe the non-breeding areas used by the overall population of Rollers in southern Africa (irrespective of their breeding origin), we used occurrence data available from the Southern African Bird Atlas Project (SABAPı; Harrison et al. 1997). Although there is currently an ongoing second phase of the SABAP atlas, to date the SABAPI has a more complete coverage of our study area and was selected for this reason. We complemented this dataset with available records from the open source database GBIF (Global Biodiversity Information Facility; http://www.gbif. org/). In the GBIF database, we discarded records from bird collections and kept only data I) with reported location accuracy; 2) from 2000 to 2014 in order to describe recent Roller distribution, 3) collected between 1 December and 28 February to ensure that observations belong to individuals residing on their non-breeding area (Rodriguez-Ruiz et al. 2014, Table I) and not to individuals recorded while on passage that may not be actually staying in the area (Lee and Barnard 2017); and 4) occurring within the southern African range (latitude: $15^{\circ}$ to $36^{\circ} \mathrm{S}$; longitude: $11^{\circ}$ to $34^{\circ} \mathrm{E}$ ). Records of Rollers wintering north of $15^{\circ} \mathrm{S}$ are anecdotal, and restricted to very few locations, so sampling cannot be considered representative for modelling (see model requirements below). In total, we built a dataset consisting of 1,167 occurrences obtained from these sources, which we used to model the potential suitable distribution of the overall population in southern Africa.

\section{Environmental data}

We used 14 environmental variables to model the ecological niche of the species. We obtained climatic variables from the WorldClim database (Hijmans et al. 2005), which includes 19 bioclimatic predictor layers summarising annual trends, seasonality and extremes in temperature and precipitation. As many of these variables were correlated, we extracted the values from all the 19 bioclimatic predictors corresponding to our occurrence records and selected six independent climate variables for analyses (using regression trees and variance inflation factor analyses to avoid multi-collinearity among selected variables). Besides climatic, topographic and habitat variables, distance to rivers and road density were included for their a priori biological relevance, as these are known to influence habitat preferences of Rollers during breeding (Cramp 1998, Rodriguez et al. 2011). A detailed list of variables is in Table 1 . 
Table 1 . Variables used in the ecological niche models.

\begin{tabular}{|c|c|c|}
\hline Layers & Variable & Source \\
\hline Climatic variables & $\begin{array}{l}\text { BIO } 1 \text { : Annual mean temperature }\left({ }^{\circ} \mathrm{C} \times 10\right) \\
\mathrm{BIO}_{2} \text { : Mean diurnal range }\left({ }^{\circ} \mathrm{C} \times 10\right) \\
\mathrm{BIO}_{9} \text { : Mean temperature of the driest } \\
\text { quarter }\left({ }^{\circ} \mathrm{C} \times 10\right) \\
\mathrm{BIO}_{15} \text { : Precipitation seasonality (coefficient } \\
\text { of variation of monthly precipitation) } \\
\text { BIO } 17 \text { : Precipitation of the driest quarter }(\mathrm{mm}) \\
\text { BIO19: Precipitation of the warmest quarter }(\mathrm{mm})\end{array}$ & $\begin{array}{l}\text { BioClim database (http://cres. } \\
\text { anu.edu.au/outputs/anuclim/ } \\
\text { doc/bioclim.html) }\end{array}$ \\
\hline Topographic variables & $\begin{array}{l}\text { Slope (degrees) } \\
\text { Aspect (continuous variable between o and } \\
\left.360^{\circ}\right)^{* * *} \\
\text { Road density (\% of surface covered by roads per } \\
\text { cell of size } 15 \text { arc-min) } \\
\text { Distance to rivers }(\mathrm{km})\end{array}$ & $\begin{array}{l}\text { Derived from the digital elevation } \\
\text { model from BioClim data } \\
\text { base* } \\
\text { UNEP/FAO Desertification } \\
\text { Assessment and Mapping Project } \\
\text { (http://www.fao.org/geonetwork/) }\end{array}$ \\
\hline Habitat & $\begin{array}{l}\text { Land cover } \\
\text { Land cover diversity } \\
\text { Tree cover }(\%) \\
\text { Herbaceous cover }(\%)\end{array}$ & GlobCover 2009 v2.3 \\
\hline
\end{tabular}

${ }^{*}$ Calculated with QGIS (QGIS 2015)

${ }^{* *}$ Calculated according to the eight surrounding pixels for every grid cell

${ }^{* * *}$ Pixels with a slope less than $2^{\circ}$ were considered as flat (no aspect)

\section{Spatial resolution}

All environmental variables were rescaled by overlaying them with a grid of 15 arc-min cell size (approximately $25 \times 25 \mathrm{~km}$ ) including almost all sub-equatorial Africa (see coordinates range considered above). This scale was chosen to fit the resolution of the SABAPI census method that included most of the locations of wintering Rollers in southern Africa. The resampling of the data to adjust the scale was performed using the nearest-neighbour method for the categorical variable land cover and the bilinear interpolation method for the continuous variables. For the road density variable, we used the number of roads per cell at the given resolution.

\section{Ecological niche models}

We modelled the ecological niche of Rollers in southern Africa using the MaxEnt software (version 3.3.3k; Phillips et al. 2006) implemented in the R package dismo. MaxEnt uses presence-only data to estimate the probability distribution of a species and a maximum entropy modelling approach (Phillips et al. 2006; Elith et al. 2011). It also requires a set of background points where species occurrence was not measured to contrast against presences, from which it predicts the environmental conditions occupied by the species in proportion to their availability in the landscape (Elith et al. 2011). MaxEnt is also reported to have the best performance when dealing with small sample sizes (Hernández et al. 2006). This method works under two key assumptions: a) sampling is either random or representative throughout the landscape, and b) detection probability is constant across sites (Yackulic et al. 2013). By using satellite-tracking data these two assumptions are met, as tracked birds represent a random sample of the breeding population. These assumptions are also fulfilled by data from online databases. Indeed, the SABAPI had a constant effort along the area considered in this study and Rollers are conspicuous birds that almost invariably perch in exposed places (i.e. trees and/or pylons) close to bush-cleared grassland in southern Africa (Herremans et al. 1993), thus making their detection an easy task. 
We created a set of 1 , ooo points randomly distributed over the considered extent of southern Africa using the function randomPoints included in dismo package in $\mathrm{R}$, checking for non-overlap with presences (i.e. grey points in Figure I). Occurrence and background datasets were separated into five groups. We randomly selected four of these groups for model fitting $(80 \%$ of data for training) and one group for testing the resultant model $(20 \%$ of the data), alternatively changing the training and testing groups for each replication. The models were run using logistic output format, with 500 iterations set for model convergence. Variable importance was measured using the jackknife method. Models performances were evaluated using the area under the receiver-operating curve (AUC) (Fielding and Bell 1997), for which values above 0.75 are usually considered as of good performance and values above 0.90 are considered very good. Regulation multiplier $(\beta)$ was previously selected by exploring a pool
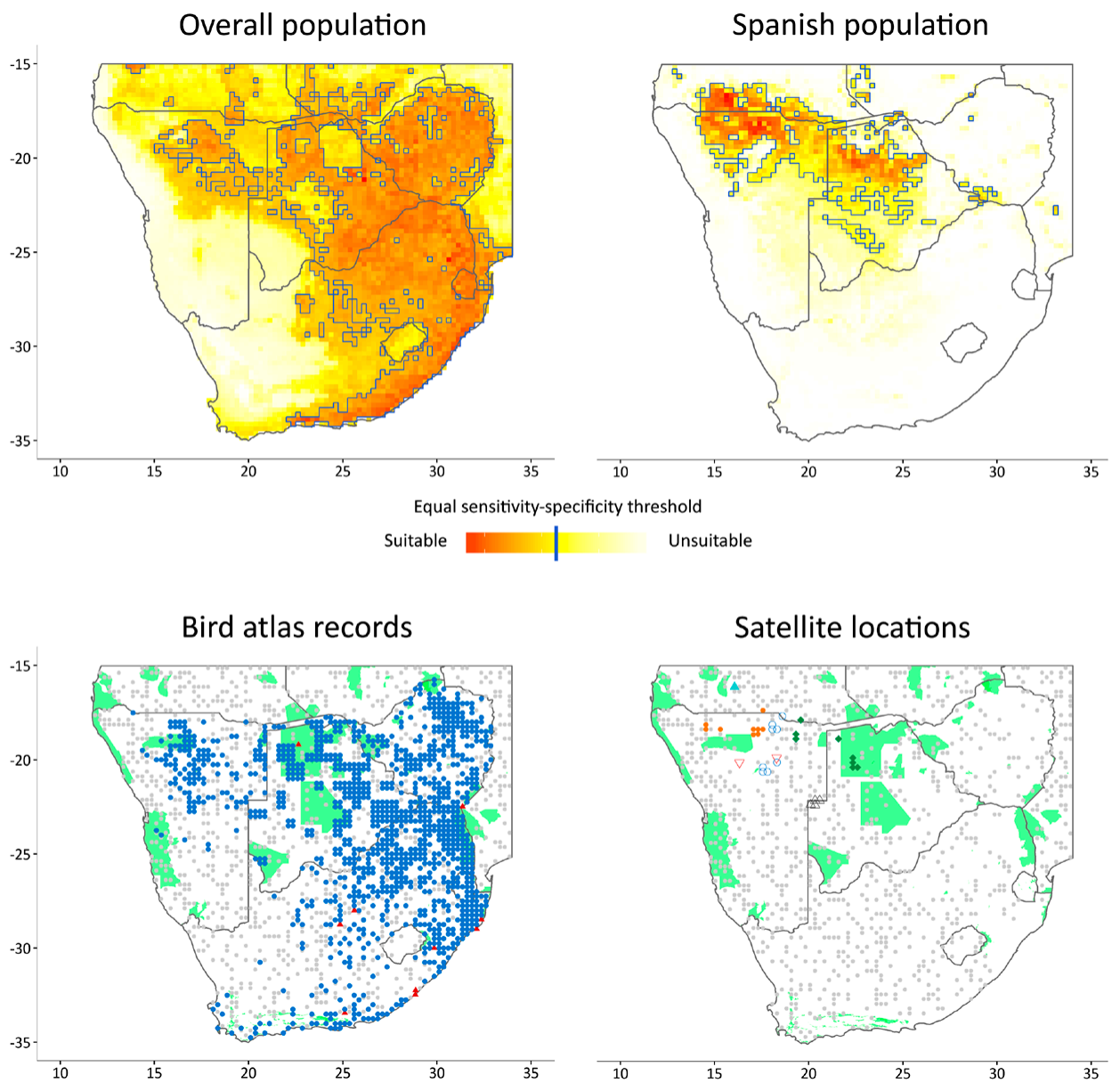

Figure 1 . Results of the ecological niche models for the overall population (upper-left) and for the Spanish population (upper-right) in Southern Africa. Map at bottom-left shows the records from the SABAP (blue dots) and GBIF (red triangles) database and their associated background points (grey dots). Map at bottom-right shows the locations of the satellite-tracked Rollers (individuals in different shape and colour) and their associated background points (grey dots). The existing protected areas with international recognition are shown in green in the two maps at bottom (UNEP-WCMC 2010). 
of models using a range of $\beta$ values from I to Io in steps of $0.5 . \beta$ was chosen attending to AUC, AICc and smooth response curves.

MaxEnt produces a map showing the relative suitability of species occurrence, giving a value for every grid cell that ranges from o to 1 . We used the equal sensitivity-specificity threshold (ESS) as a criterion of suitability: regions of the map with values above this threshold were considered as suitable for the species (Bean et al. 2012, Cao et al. 2013). We evaluated the relative contribution of variables to the model and how they affected the model predictions attending to the response curves given by MaxEnt.

\section{Land cover use}

Firstly, we use the 33 filtered satellite locations of tracked Spanish Rollers to identify which land cover types are actually used during the wintering period and whether there are individual preferences. We also used the generated maps to estimate the proportions of land cover types used by the overall population and by the Spanish population. We did so by superposing the suitable areas for the species (occurrence probability > ESS) onto the GlobCover 2009 v2.3 land cover map using $\mathrm{R}$.

\section{Protected areas}

We assessed the extent to which suitable areas for the species overlapped with extant PAs, using nationally recognized PAs listed in the 2010 World Database on Protected Areas (IUCN and UNEP-WCMC 2010). We only considered PAs with IUCN classifications, Ramsar Convention Sites, World Heritage Sites, UNESCO-MAB Biosphere Reserves and sites within other international conventions. A total of 95 PAs covered $11.08 \%$ of the total study area (Figure 1 ).

\section{Results}

\section{Ecological niche models}

The identified suitable wintering area for the Spanish population was relatively narrow and located mainly in the south of Angola, north of Namibia and central Botswana, with scattered small locations in Zambia, Zimbabwe and Mozambique (Figure 1 ). The climatic variables that contributed most to the ecological niche model (> $5 \%$ ) were mean annual temperature and precipitation in the driest quarter (II.68 and $8.69 \%$, respectively; Table 2). Mean annual temperature was positively correlated to probability of occurrence, with a turning point at $23^{\circ} \mathrm{C}$. Precipitation in the driest quarter was inversely correlated until $40 \mathrm{~mm}$, when the curve stabilizes (Figure 2). The non-climatic variables that contributed most to the model were land cover, slope and tree cover $(34.33 \%, 24.27 \%$ and $15.67 \%$, respectively; Table 2). The land cover type with highest probability of occurrence was the savanna. Probability of occurrence decreased with increasing slope; when the slope was greater than $2 \%$ the probability of occurrence was almost zero. Probability of occurrence increased with tree cover until $5 \%$, but then decreased above this threshold value (Figure 2). The discriminatory power of the model for the Spanish population was very good, as assessed by the area under the curve (AUC $=0.927$ ).

The identified suitable wintering areas for the overall population (irrespective of breeding origin) consisted mainly of the eastern part of southern Africa, Zimbabwe, eastern Botswana and the north-east and east coast of South Africa, as well as isolated patches in the north of Namibia (Figure 1). The most important variables contributing to this model were tree cover, temperature in the warmest quarter, precipitation in the driest quarter and temperature in the driest quarter $(53.28 \%, 14.29 \%, 8.6 \%$ and $8.24 \%$, respectively; Table 2$)$. Tree cover was initially positively correlated to probability of occurrence, reaching a turning point around 10\% of coverage, when the 
Table 2. Model parameters and contribution (\%) of environmental variables to the ecological niche models. Two separate models were developed to identify suitable areas for the overall population and for the Spanish population of Rollers. Most important variables in each model are shown in bold (i.e. Variable importance $>5 \%$, in terms of contribution to the model).

\begin{tabular}{lcc}
\hline & Overall population & Spanish population \\
\hline Regularization multiplier & 2 & 2.5 \\
AUC & 0.82 & 0.93 \\
Equal sensitivity-specificity threshold & 0.48 & 0.34 \\
Model train & & 26 \\
n presences & 934 & 800 \\
n absences & 800 & \\
Model Test & & 7 \\
n presences & 233 & 200 \\
n absences & 200 & \\
Variable importance & & $\mathbf{1 1 . 6 8}$ \\
Annual mean temperature & 1.58 & 0.59 \\
Aspect & 0.19 & 1.13 \\
Distance to rivers & 0.04 & 0.01 \\
Diurnal range & 2.63 & 0.00 \\
Land cover diversity & 1.12 & $\mathbf{3 4 . 3 8}$ \\
Land cover & 3.48 & $\mathbf{8 . 6 9}$ \\
Precipitation in the driest quarter & $\mathbf{8 . 6 0}$ & 2.32 \\
Precipitation seasonality & $\mathbf{1 . 3 9}$ & 0.97 \\
Precipitation in the wettest quarter & $\mathbf{1 4 . 2 9}$ & 0.13 \\
Road density & 2.73 & $\mathbf{2 4 . 2 7}$ \\
Slope & 0.48 & 0.00 \\
Temperature in the driest quarter & $\mathbf{8 . 2 4}$ & 0.16 \\
Herbaceous cover & $\mathbf{1 . 9 3}$ & $\mathbf{1 5 . 6 7}$ \\
Tree cover & $\mathbf{5 3 . 2 8}$ &
\end{tabular}

curve stabilises. The three climatic variables were positively correlated with occurrence probability, but precipitation in the warmest quarter and temperature in the driest quarter reached turning points at $200 \mathrm{~mm}$ and $18^{\circ} \mathrm{C}$, respectively (Figure 2). The model for the overall population also performed well $(\mathrm{AUC}=0.818)$.

\section{Land cover use}

Three land cover types were selected by the tracked Rollers: grassland, savanna and shrubland, yet we found individual differences among them $\left(\chi_{10}^{2}=18.74, P=0.04\right)$. Five individuals used mainly grassland and savanna, whereas one roller used only shrubland. For models, considering both the Spanish population and the overall population, we found that the savanna was the primarily used land cover $(53.10 \%$ and $56.55 \%$, respectively), followed by grasslands (21.52\% and $12.12 \%)$. Shrublands also appeared to be important for the Spanish population (18.06\%), whereas mosaics of croplands/grasslands and dry croplands were important for the overall population (11.72\% and $6.45 \%$, respectively). All these land cover types represented more than $85 \%$ of the total predicted suitable areas (Figure 3).

\section{Protected areas}

Only one tracked bird actually used PAs during its wintering period (four out of eight locations inside PAs), yet birds often wintered in places close to PAs: 18 out of 33 locations were within $100 \mathrm{~km}$ of a PA boundary, and the distance between satellite locations and the nearest PA was $66.7 \mathrm{~km}$ (range 0-223.9). For the Spanish population, $18.37 \%$ of the identified suitable area was 


\section{Overall population}
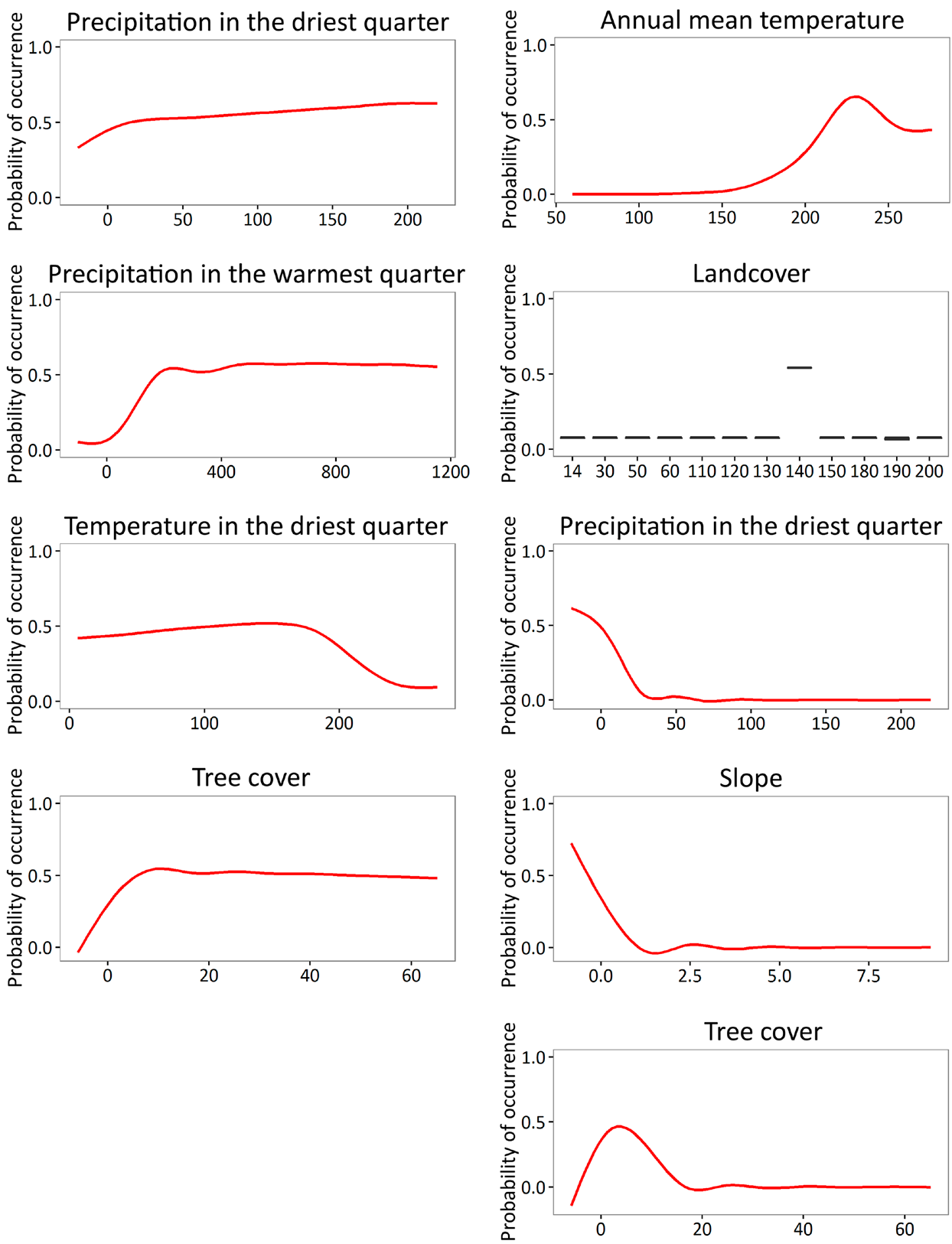

Figure 2. Partial response curves representing the relation between probability of occurrence of the Spanish population (left) and the overall population (right) and the five most important factors contributing to the models. Units are given in Table 2. 


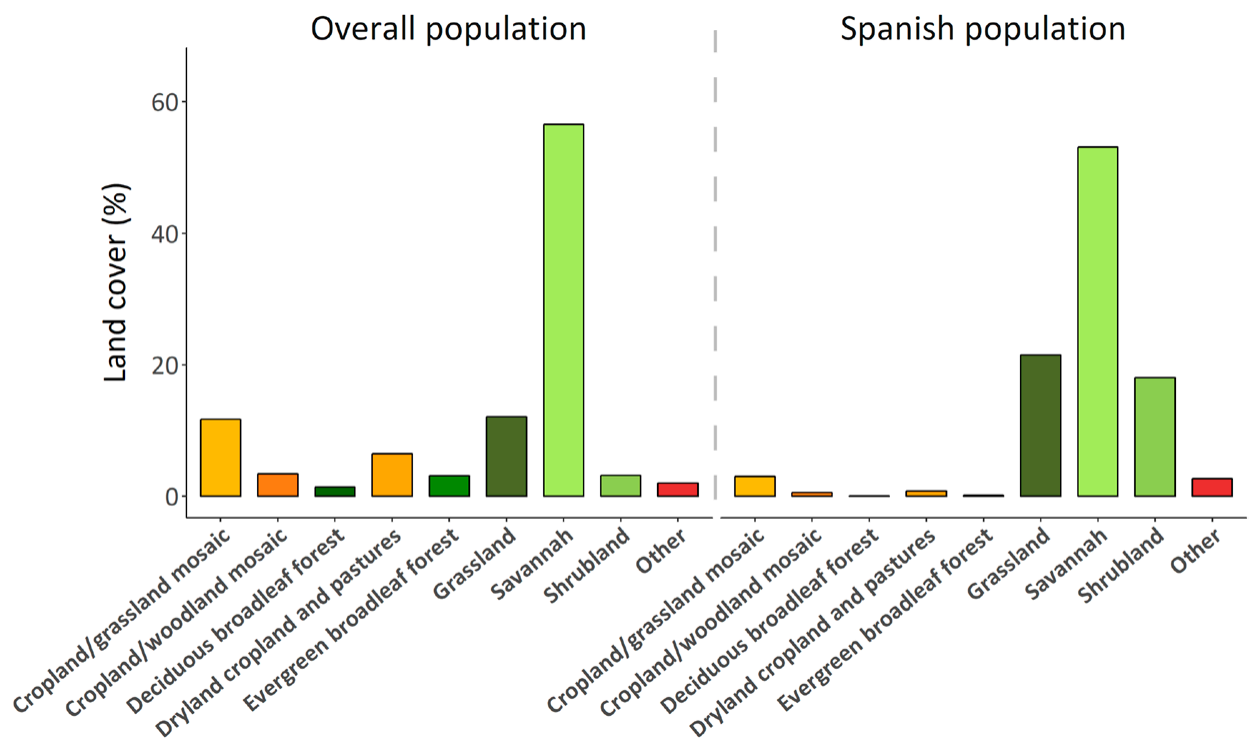

Figure 3. Proportion of land cover areas included in the optimal distributions predicted by MaxEnt for the overall population and for the Spanish population. Greenish colours represent non-managed land cover types, yellowish colours represent man-managed land cover types.

included within PAs (26 of 95 PAs; see Table 4 for details of the most relevant PAs). For the overall population, however, only $9.58 \%$ of the predicted suitable area was included within PAs (66 of 95 PAs).

Savanna, grassland and shrubland represent $77 \%$ of the total study area, but only $10 \%$ of this area was covered by PAs. The proportion of these land covers that was protected compared with the proportion that was outside PAs did not differ from that of other land cover types, such as pastures or cropland $\left(\chi^{2}{ }_{11}=14.724, P=0.195\right)$, unlike wetlands, which were almost entirely protected (Table 3 ).

\section{Discussion}

\section{Suitable non-breeding areas for Rollers}

To our knowledge, this is the first study combining two different perspectives (i.e. satellite-tracking and bird atlases) to estimate and identify suitable areas and potential threats to an endangered migratory bird species. The suitable non-breeding areas for the Spanish population were located in the north-western part of southern Africa, whereas the overall population occupied a wider region, from central southern Africa to the east and from north to the south along the eastern coast of Africa. We found little overlap between the two predicted suitable areas. However, comparisons must be made carefully, because input data for each model came from different sources and hence likely had different probabilities of detection. The under-representation of the species in the north-western region in the model for the overall population may be a consequence of a differential sampling effort in the $\mathrm{SABAP}_{1}$ in these regions, or of biases due to the limitations of satellite data from only six individuals. A higher sample of tracked individuals, perhaps including Rollers breeding in populations close to the ones sampled here, and a higher participation in the censuses for the most remote areas in southern Africa could provide a more unbiased representation of the distributional range of the species during wintering. Nonetheless, these results support 
Table 3. Land cover composition in study area, protected areas coverage of each land cover type and number of satellite locations from tracked birds that falls within each land cover type.

\begin{tabular}{|c|c|c|c|c|c|c|c|c|c|}
\hline Land cover type & Land cover composition (\%) & Proportion protected (\%) & $\begin{array}{l}\text { Satellite locations within } \\
\text { each land cover }\end{array}$ & Bird \#I & Bird \#2 & Bird \#3 & Bird $\#_{4}$ & Bird $\#_{5}$ & Bird \#6 \\
\hline Urban areas & 0.08 & 1.32 & o & - & - & - & - & - & - \\
\hline Dryland cropland and pastures & 3.66 & 7.19 & o & - & - & - & - & - & - \\
\hline Cropland/grassland mosaic & 5.63 & $4 \cdot 37$ & o & - & - & - & - & - & - \\
\hline Cropland/woodland mosaic & 3.26 & $7 \cdot 33$ & o & - & - & - & - & - & - \\
\hline Grassland & 17.83 & 4.6 & 11 & 3 & o & 4 & 1 & 3 & o \\
\hline Shrubland & 19.7 & 10.5 & 8 & 3 & o & 1 & o & o & 4 \\
\hline Savanna & 39.62 & 12.37 & 14 & 3 & 1 & 4 & 1 & 5 & o \\
\hline Deciduous broadleaf forest & 1.72 & 17.19 & o & - & - & - & - & - & - \\
\hline Evergreen broadleaf forest & 1.5 & 7.16 & o & - & - & - & - & - & - \\
\hline Water & 1.54 & 15.03 & o & - & - & - & - & - & - \\
\hline Wooded wetland & 0.09 & 99.41 & o & - & - & - & - & - & - \\
\hline Barren or sparsely vegetated & $5 \cdot 39$ & 29.28 & o & - & - & - & - & - & - \\
\hline
\end{tabular}


the previous patterns found using tracking devices suggesting that birds from different breeding populations spend their winter in different but overlapping areas (Finch et al. 2015). From our data, we infer that birds breeding in south-western populations migrate to the northwestern part of the total non-breeding range area for the species. Therefore, birds from other breeding populations (i.e. Central or Eastern Europe) are probably those spending the non-breeding season farther east (see Figure 1- map of the overall population). This idea is supported by a recent study of the migration of Rollers breeding in Bulgaria, Cyprus, Latvia and Montenegro, showing that these birds winter in southern Africa farther east than Rollers breeding in Spain (Finch et al. 2015).

The ecological niche models indicate that the non-breeding distribution of Rollers is strongly influenced by climatic variables. Both precipitation and temperature had an important weight when predicting the distribution of Rollers. Therefore, changes in the general patterns of these climatic variables might affect the extent of suitable areas for the species through indirect changes in habitat or in prey abundance (Huntley et al. 2006, 2008, Chen et al. 2011). However, this pattern is not consistent when considering the Spanish population, for which climatic variables appeared less relevant. This may be due to the less diverse climatic conditions in a more limited band of latitude, which makes other variables, such as land cover, more relevant. Precipitation in the driest quarter was an important predictor in the models of the Spanish population and the overall population of Rollers, although the tolerance to this variable (i.e. response curve) differed. Indeed, the Spanish population showed a narrower range of tolerable conditions (between o and $25 \mathrm{~mm}$ ) than the overall population (between o and $200 \mathrm{~mm}$; Figure 2), perhaps because the response curve for the overall population describes the summed tolerance of each separate breeding population. Two alternative explanations for these different thresholds in the wintering areas are possible: 1 ) individuals track niches with conditions and resources more similar to those of their breeding grounds, driven by population-specific adaptations (Price and Gross 2005, Monahan and Tingley 2012); or 2) populations distribution in the wintering quarters reflects the longitudinal distribution in their breeding areas following a parallel migration (Finch et al. 2015), making the climatic conditions found in Africa a collateral consequence and not a real tolerance range.

Besides climatic variables, tree cover appears as an important factor that influences the ecological niche and distribution of both the overall population and the Spanish population. Suitability is higher when tree cover is low for the Spanish population, while the tree cover threshold appears to be higher for the overall population (Figure 2). Rollers usually use open landscapes with sparse trees in their breeding grounds (Avilés and Costillo 1998) and this preference also seems to occur during the non-breeding season, at least for the Spanish population. In the case of the Spanish population, slope and land cover are the most important variables determining the suitable area. Spanish Rollers seem to be restricted to flat areas and savanna. Even though Rollers are known to choose breeding territories next to watercourses (Cramp 1998), which usually present slopes, these conditions do not necessarily apply to non-breeding areas, where Rollers may find flat areas with scattered trees as a suitable landscape due to the availability of perches and a better line of sight to forage.

\section{Roller land cover use in southern Africa}

During the non-breeding season (December-February), Spanish Rollers used land cover types characterised by a high proportion of natural vegetation (savanna, grassland and shrubland, but the predicted suitable areas for the overall population overlapped with a higher proportion of anthropogenically managed land cover types (Figure 3). This pattern may be explained by the relative abundance of land cover types within each particular range. In the eastern part of southern Africa, a high proportion of savanna, grassland and shrubland has been progressively converted into crops due to high human population density (Lambin et al. 2001, Linard et al. 2012). In these low-intensive farming areas, the replacement of natural savanna leads to large increases in the availability of prey species for insectivorous birds (e.g. grasshoppers; 
Hulme 2007). However, this also means more insect pests for crops and a greater use of pesticides in cultivated areas to combat these, which may have an indirect negative effect on insectivorous birds in general, and Rollers in particular (Everts 1990, Mullie and Keith 1993, Avilés and Parejo 2004, Newton 2004). Organochlorine pesticides (DDT and DDE) have been recently detected in avian predators from southern Africa, indicating that these compounds still represent a risk, either through an illegal use outside malaria areas or their long persistence in the environment (García-Heras et al. 2018).

\section{Overlap with conservation areas}

Savanna, grassland and shrubland are proportionally less protected than wetlands, but are also very important to migratory birds like Rollers. In fact, this is not the first study highlighting the need of increasing the protection of crucial habitats for migratory birds of semiarid areas (Limiñana et al. 2015). Our results show that the current network of PAs covers only a tenth of the non-breeding areas identified as most suitable for the overall population of Rollers in southern Africa. The modelled optimal distribution of the Spanish population, however, benefited from a relatively greater degree of protection, with almost $20 \%$ of most suitable areas being currently included within PAs. Compared with other studies in Africa conducted on species with similar requirements, there is still room for improvement in protection coverage (Limiñana et al. 2015), although Rollers find a better scenario than other species (Limiñana et al. 2012). Interestingly, Rollers also used areas close to PA boundaries. The reasons for this should be elucidated, but this observation suggests that a small expansion of the PAs could be a benefit for this species. The relatively high occurrence of Rollers outside PAs has several mutually non-exclusive explanations: 1 ) current PAs are mainly designed to protect charismatic megafauna, and, therefore, have an insufficient coverage of suitable habitats for long-distance migrant birds; 2) unprotected areas are attracting Rollers due to their high availability of perches for hunting (e.g. power lines along roads). A previous study has found that availability of perch sites is a factor favouring breeding territory choice for Spanish Rollers (Avilés and Costillo 1998). PAs in Africa are in areas with low human population density and, therefore, have a reduced network of roads and associated power lines and may provide Rollers with a low number of perches (see above); 3 ) unprotected areas might be attracting Rollers because competition with resident insectivores could be lower than inside PAs (Herremans 1998); or 4) because the higher agricultural intensification in unprotected areas leads to an increase of plant material that facilitates the accidental introduction of foreign insect arthropod pests (Abate et al. 200o) which may constitute new feeding opportunities for Rollers.

Between $74 \%$ and $82 \%$ (Spanish population and overall population, respectively) of the estimated suitable area for Rollers which is under coverage of PAs is categorised as National Park or Ramsar site. The Okavango Delta System in Botswana appears to be one PA that contains larger proportions of predicted suitable area for both the Spanish population and the overall populations of Rollers (Table 4). This PA is listed as a Ramsar and UNESCO World Heritage Site, however, its conservation status is threatened by climate change and an increasing pressure to satisfy the demand for water and grazing lands of a growing surrounding population (BirdLife International 2018a). Focusing on Rollers, threats that may compromise the suitability of this area are overgrazing, clear-cutting and the use of insecticides that could reduce prey availability (Thieme et al. 2005). The Kruger National Park in north-eastern South Africa, Kalahari National Park in central Botswana and Etosha National Park in north-western Namibia, also protect large suitable areas for Rollers, although only Kalahari enjoys a favourable conservation status (BirdLife International 2018b; 2018c; 2018d). Between $18 \%$ and $26 \%$ of the suitable area for Rollers under protection are categorised as minor parks (e.g. nature reserves and game reserves) and their conservation status and their contribution to the welfare of Rollers in them should be assessed carefully. 
Table 4. List of the five most important protected areas contributing to the predicted suitable areas (PSA) for the overall population and for the Spanish population of Rollers.

\begin{tabular}{|c|c|c|c|c|c|}
\hline Protected area & $\begin{array}{l}\text { Total area } \\
(\mathrm{km} 2)\end{array}$ & $\begin{array}{l}\text { Area included in } \\
\text { the model }(\mathrm{km} 2)\end{array}$ & $\begin{array}{l}\text { Proportion of PSA } \\
\text { included in PA (\%) }\end{array}$ & Designation & $\begin{array}{l}\text { International } \\
\text { category }\end{array}$ \\
\hline \multicolumn{6}{|l|}{ Overall population } \\
\hline Okavango Delta System & 64,363 & 54,880 & $3 \cdot 77$ & Ramsar Site & $\begin{array}{c}\text { UNESCO World } \\
\text { Heritage Site }\end{array}$ \\
\hline Kruger National Park & 19,260 & 19,420 & 1.33 & National Park & IUCN: II \\
\hline Central Kalahari & 52,476 & 13,560 & 0.93 & National Park & IUCN: Ib \\
\hline Hwange & 14,776 & 11,234 & 0.77 & National Park & IUCN: II \\
\hline Etosha & 23,063 & 5,817 & 0.40 & National Park & IUCN: II \\
\hline \multicolumn{6}{|l|}{ Spanish population } \\
\hline Okavango Delta System & 64,363 & 51,523 & 9.00 & Ramsar Site & $\begin{array}{c}\text { UNESCO World } \\
\text { Heritage Site }\end{array}$ \\
\hline Central Kalahari & 52,476 & 30,083 & 5.25 & National Park & IUCN: Ib \\
\hline Etosha & 23,063 & 20,158 & 3.52 & National Park & IUCN: II \\
\hline Makgadikgadi Pans & 4,916 & 4,905 & 0.86 & National Park & IUCN: Ib \\
\hline Chobe & 10,562 & 3,958 & 0.69 & National Park & IUCN: Ib \\
\hline
\end{tabular}

Summing up, PAs in southern Africa cover, on average, a low proportion of the suitable habitat for threatened species (Beresford et al. 2011, Runge et al. 2015). This seems to be also the case for the European Roller, until very recently considered as 'Near Threatened' by IUCN and currently considered as 'Vulnerable' in Spain. Given the extensive area used by the overall population of Rollers during wintering, conservation measures directed to manage the landscape on a broad scale may be preferable to the investing the limited economical resources dedicated to conservation into extending the existing PA network. For instance, developing agricultural policies that reduce intensification and protect the grasslands would be beneficial. We also point out that different breeding populations may face different conservation threats in their respective non-breeding areas and that a conservation plan focusing on the most suitable areas for the species in general may not be sufficient to protect all breeding populations. We highlight the importance of analysing the particular requirements of each population to elaborate an integrated and effective conservation plan for the species as a whole, which is more relevant, if possible, when there is some migratory connectivity, as in the case of the Roller (Finch et al. 2015). In this sense, attending to the wide predicted wintering area, international cooperation is essential to make a joined effort in fulfilling the conservation needs of this species, as well as those of other sub-Saharan migrants. Further research is also needed for locating key stopover areas for different Roller populations and assessing their protection status during this critical stage of their life cycle.

\section{Acknowledgements}

We thank Dan Chamberlain, Tom Finch, Graeme Buchanan and two anonymous reviewers for their comments that helped in shaping this manuscript. DP and JMA were funded by the Spanish Ministry of Education and Science/FEDER through the projects CGL2008-00718 and by the Government of Extremadura through the project TA13002 to DP. All the information about tagged Rollers in Spain has been obtained in the framework of the 'Migra' program (www.migraciondeaves.org/en/) developed by SEO/BirdLife, coordinated by Juan Carlos del Moral, and financed by Iberdrola Foundation. The Extremadura Regional Government provided information on one individual. Manuel Aguilera, Jaume Bonfil, Gerard Bota, Pedro Bustamante, Jesús Fernández, José Antonio Fimia, María José Herrero, Jesús Morena, Juan Carlos Perlado, Sergio Romero and Chema Traverso helped during fieldwork. Domingo Rivera, José María Abad and Toribio Álvarez (Junta de Extremadura) made fieldwork and downloaded all the information from the individual from Extremadura. 


\section{References}

Argos (2007) Argos user's manual. Ramonville Saint-Agne, France: Collecte Localisation Satellites.

Avilés, J. M. and Costillo, E. (1998) Selection of breeding habitats by the Roller (Coracias garrulus) in farming areas of the southwestern Iberian peninsula. Vogelwarte 39: 242-247.

Avilés, J. M. and Parejo, D. (2004) Farming practices and Roller Coracias garrulus conservation in south-west Spain. Bird Conserv. Internatn. 14: 173-181.

Bean, W. T., Stafford, R. and Brashares, J. S. (2012) The effects of small sample size and sample bias on threshold selection and accuracy assessment of species distribution models. Ecography 35: 250-258.

Beresford, A. E., Buchanan, G. M., Donald, P. F., Butchart, S. H. M., Fishpool, L. D. C. and Rondinini, C. (2011) Poor overlap between the distribution of Protected Areas and globally threatened birds in Africa. Anim. Conserv. 14: 99-107.

Beresford, A. E., Eshiamwata, G. W., Donald, P. F., Balmford, A., Bertzky, B., Brink, A. B., Fishpool, L. D. C., Mayaux, P., Phalan, B., Simonetti, D. and Buchanan, G. M. (2013) Protection reduces loss of natural land-cover at sites of conservation importance across Africa. PLoS ONE 8(5): e65370.

Birdlife International (2015) European Red List of birds. Luxembourg: Office for Official Publications of the European Community.

Birdlife International (2018a) Important Bird Areas factsheet: Okavango Delta. Downloaded from http://www.birdlife.org (http://www.birdlife.org) on 25/02/2018.

Birdlife International (2018b) Important Bird Areas factsheet: Etosha National Park. Downloaded from http://www.birdlife.org (http://www.birdlife.org) on 25/02/2018.

Birdlife International (2018c) Important Bird Areas factsheet: Central Kalahari (Kgalagadi) and Khutse Game Reserves. Downloaded from http://www.birdlife.org (http://www. birdlife.org) on 25/02/2018.

Birdlife International (2018d) Important Bird Areas factsheet: Kruger National Park and adjacent areas. Downloaded from http://www.birdlife.org (http://www.birdlife. org) on 25/02/2018.

Burfield, I. and Van Bommel, F. (2004) Birds in Europe: population estimates, trends and conservation status. Cambridge, UK: BirdLife International. (BirdLife Conservation series no. 12).

Cao, Y., DeWalt, R. E., Robinson, J. L., Tweddale, T., Hinz, L. and Pessino, M. (2013) Using Maxent to model the historic distributions of stonefly species in Illinois streams: The effects of regularization and threshold selections. Ecol. Model. 259:30-39.

Catry, I., Catry, T., Granadeiro, J. P., Franco, A. M. A. and Moreira, F. (2014) Unravelling migration routes and wintering grounds of European Rollers using light-level geolocators. J. Ornithol. 155: 1071-1075.

Chen, I. C., Hill, J. K., Ohlemuller, R., Roy, D. B. and Thomas, C. D. (2011) Rapid range shifts of species associated with high levels of climate warming. Science 333: 1024-1026.

Cramp, S. (1998) The complete birds of the Western Palearctic on CD-ROM. Oxford, UK: Oxford University Press.

Elith, J., Phillips, S. J., Hastie, T., Dudik, M., Chee, Y. E. and Yates, C. J. (2011) A statistical explanation of MaxEnt for ecologists. Divers. Distrib. 17: 43-57.

Emmenegger, T., Mayet, P., Duriez, O. and Hahn, S. (2014) Directional shifts in migration pattern of Rollers (Coracias garrulus) from a western European population. J. Ornithol. 155: 427-433.

Everts, J. W. (1990) Environmental effects of chemical locust and grasshopper control. A pilot study. Rome, Italy: FAO.

Fielding, A. H. and Bell, J. F. (1997) A review of methods for the assessment of prediction errors in conservation presence/absence models. Environ. Conserv. 24: 38-49.

Finch, T., Saunders, P., Avilés, J. M., Bermejo, A., Catry, I., De la Puente, J., Emmenegger, T., Mardega, I., Mayet, P., Parejo, D., Racinskis, E., Rodríguez-Ruiz, J., Sackl, P., Schwartz, T., Tiefenbach, M., Valera, F., Hewson, C., Franco, A. and Butler, S. J. (2015) A panEuropean, multipopulation assessment of migratory connectivity in a near-threatened migrant bird. Divers. Distrib. 21: 1051-1062. 
Garcelon, D. K. (1985) Mounting backpack telemetry packages on bald eagles. Arcata, CA: Institute for Wildlife Studies.

García-Heras, M. S., Simmons, R. E., Arroyo, B., Camarero, P., Mateo, R., Mougeot, F. (2018) Blood concentrations of PCBs and DDTs in an avian predator endemic to southern Africa: associations with habitat, density of electric transformers and diet. Environ. Poll. 232: 440-449.

Harrison, J. A., Allan, D. G., Underhill, L. H., Herremans, M., Tree, A. J., Parker, V. and Brown, C. J. (1997) The atlas of Southern African birds (Volume 1). Johannesburg, South Africa: BirdLife South Africa.

Hernández, P. A., Graham, C., Master, L. L. and Albert, D. L. (2006) The effect of sample size and species characteristics on performance of different species distribution modeling methods. Ecography 29: 773-785.

Herremans, M. (1998) Conservation status of birds in Botswana in relation to land use. Biol. Conserv. 86: 139-160.

Herremans, M., Brown, C. J., Borello, W. D. and Herremans-Tonnoeyr, D. (1993) The abundance of European Rollers CoraciasGarrulus in Botswana and Namibia. Ostrich 64: 93-94.

Hijmans, R. J., Cameron, S. E., Parra, J. L., Jones, P. G. and Jarvis, A. (2005) Very high resolution interpolated climate surfaces for global land areas. Internatn. J. Climatol. 25: 1965-1978.

Hulme, M. F. (2007) The density and diversity of birds on farmland in West Africa. PhD thesis. University of St Andrews, UK.

Huntley, B., Collingham, Y. C., Green, R. E., Hilton, G. M., Rahbek, C. and Willis, S. G. (2006) Potential impacts of climatic change upon geographical distributions of birds. Ibis 148: 8-28.

Huntley, B., Collingham, Y. C., Willis, S. G. and Green, R. E. (2008) Potential impacts of climatic change on European breeding birds. PLOS ONE 3(1): eI439.

IUCN and UNEP-WCMC (2010) The world database on protected areas (WDPA). Cambridge, UK: UNEP-WCMC. Available at: http://www.protectedplanet.net/

Keith, S., Urban, E. K. and Fry, C. H. (1988) The birds of Africa. Vol. 3: Parrots to woodpeckers. London, UK: Academic Press.
Klaassen, R. H. G., Hake, M., Strandberg, R., Koks, B., Trierweiler, C., Exo, K. M., Bairlein, F. and Alerstam, T. (2014) When and where does mortality occur in migratory birds? Direct evidence from long- term satellite tracking of raptors. J. Anim. Ecol. 83:176-184.

Kovacs, A., Barov, B., Orhun, C. and GalloOrsi, U. (2008) International species action plan for the European Roller Coracias garrulus garrulus. Besenyotelek, Hungary.

Lambin, E. F., Turner, B. L., Geist, H. J., Agbola, S. B., Angelsen, A., Bruce, J. W., Coomes, O. T., Dirzo, R., Fischer, G., Folke, C., George, P. S., Homewood, K., Imbernon, J., Leemans, R., Li, X. B., Moran, E. F., Mortimore, M., Ramakrishnan, P. S., Richards, J. F., Skanes, H., Steffen, W., Stone, G. D., Svedin, U., Veldkamp, T. A., Vogel, C. and Xu, J. C. (2001) The causes of land-use and land-cover change: moving beyond the myths. Global Environmental Change-Human and Policy Dimensions 11: 261-269.

Lee, A. T. K. and Barnard, P. (2017) How well do bird atlas reporting rates reflect bird densities? Correlates of detection from the Fynbos biome, South Africa, with applications for population estimation. Ostrich 88: 9-17.

Limiñana, R., Soutullo, A, Arroyo, B. and Urios, V. (2012) Protected areas do not fulfil the wintering habitat needs of the transSaharan migratory Montagu's harrier. Biol. Conserv. 145: 62-69.

Limiñana, R., Arroyo, B., Terraube, J., McGrady, M. and Mougeot, F. (2015) Using satellite telemetry and environmental niche modelling to inform conservation targets for a long-distance migratory raptor in its wintering grounds. Oryx 49: 329-337.

Linard, C., Gilbert, M., Snow, R. W., Noor, A. M. and Tatem, A. J. (2012) Population distribution, settlement patterns and accessibility across Africa in 2010. PLoS ONE 7(2): e31743.

Martin, T. G., Chades, I., Arcese, P., Marra, P. P., Possingham, H. P. and Norris, D. R. (2007) Optimal conservation of migratory species. PLOS ONE 2(8): e751.

Monahan, W. B. and Tingley, M. W. (2012) Niche tracking and rapid establishment of distributional equilibrium in the House Sparrow show potential responsiveness of 
species to climate change. PLoS ONE 7(7): e42097.

Mullie, W. C. and Keith, J. O. (1993) The effects of aerially applied fenitrothion and chlorpyrifos on birds in the savanna of northern Senegal. J. Appl. Ecol. 30: 536-550.

Newton, I. (2004) Population limitation in migrants. Ibis 146: 197-226.

Norris, D. R., Marra, P. P., Kyser, T. K., Sherry, T. W. and Ratcliffe, L. M. (2004) Tropical winter habitat limits reproductive success on the temperate breeding grounds in a migratory bird. Proc. Roy. Soc. B-Biol. Sci. 271: 59-64.

Phillips, S. J., Anderson, R. P. and Schapire, R. E. (2006) Maximum entropy modeling of species geographic distributions. Ecol. Model. 190: 231-259.

Price, T. and Gross, S. (2005) Correlated evolution of ecological differences among the Old World Leaf Warbler in the breeding and non-breeding seasons. Pp. 359-372 in R. Greenberg and P. P. Marra, eds. Birds of two worlds: Ecology and evolution of migration. Baltimore, USA: John Hopkins University Press.

QGIS (2015) Quantum GIS geographic information system. Open Source Geospatial Foundation Project. https://qgis.org

Rodríguez, J., Avilés, J. M. and Parejo, D. (2011) The value of nestboxes in the conservation of Eurasian Rollers Coracias garrulus in southern Spain. Ibis 153: 735-745.

Rodríguez-Ruiz, J., De la Puente, J., Parejo, D., Valera, F., Calero-Torralbo, M. A., ReyesGonzalez, J. M., Zajková, Z., Bermejo, A. and Avilés, J. M. (2014) Disentangling migratory routes and Wintering grounds of Iberian Near-Threatened European Rollers Coracias garrulus. PLoS ONE 9(12): e115615.

Runge, C. A., Watson, J. E. M., Butchart, S. H. M., Hanson, J. O., Possingham, H. P. and
Fuller, R. A. (2015) Protected areas and global conservation of migratory birds. Science 350(6265): 1255-1258.

Sala, O. E., Chapin III, F. S., Armesto, J. J., Berlow, E., Bloomfield, J., Dirzo, R., HuberSandwald, E., Huenneke, L. F., Jackson, R. B., Kinzig, A., Leemans, R., Lodge, D. M., Mooney, H. A., Oesterheld, M., Poff, N. L., Sykes, M. T., Walker, B. H., Walker, M. and Wall, D. H. (2000) Global biodiversity scenarios for the year 2100. Science 287(5459): 1770-1774.

Sanderson, F. J., Donald, P. F., Pain, D. J., Burfield, I. J. and van Bommel, F. P. J. (2006) Long-term population declines in AfroPalearctic migrant birds. Biol. Conserv. 131: 93-105.

Sillett, T. S. and Holmes, R. T. (2002) Variation in survivorship of a migratory songbird throughout its annual cycle. J. Anim. Ecol. 71: 296-308.

Terraube, J., Mougeot, F., Cornulier, T., Verma, A., Gavrilov, A. and Arroyo, B. (2012) Broad wintering range and intercontinental migratory divide within a core population of the near-threatened pallid harrier. Divers. Distrib. 18: 401-409.

Thieme, M. L., Abell, R., Burgess, N., Lehner, B., Dinerstein, E. and Olson, D. (2005) Freshwater ecoregions of Africa and Madagascar: a conservation assessment. Washington DC: Island Press.

Vickery, J. A., Ewing, S. R., Smith, K. W., Pain, D. J., Bairlein, F., Skorpilova, J. and Gregory, R. D. (2014) The decline of AfroPalaearctic migrants and an assessment of potential causes. Ibis 156: 1-22.

Yackulic, C. B., Chandler, R., Zipkin, E. F., Royle, J. A., Nichols, J. D., Grant, E. H. C. and Veran, S. (2013) Presence-only modelling using MAXENT: when can we trust the inferences? Methods Ecol. Evol. 4: 236-243. 
JUAN RODRÍGUEZ-RUIZ ${ }^{*}$, DESEADA PAREJO ${ }^{1,2}$, JESÚS M. AVILÉS²

${ }^{1}$ Área de Zoología, Departamento de Anatomía, Biología Celular y Zoología, Facultad de Ciencias, Universidad de Extremadura, Badajoz, Spain.

${ }^{2}$ Departamento de Ecología Funcional y Evolutiva, Estación Experimental de Zonas Áridas (EEZA-CSIC), Almería, Spain.

\section{FRANÇOIS MOUGEOT}

Instituto de Investigación en Recursos Cinegéticos (IREC-CSIC), Ciudad Real, Spain.

JAVIER DE LA PUENTE, ANA BERMEJO

Área de Estudio y Seguimiento de Aves, SEO/BirdLife, Madrid, Spain.

*Author for correspondence; e-mail:juanrodruiz@gmail.com

Received 24 April 2017; revision accepted 6 May 2018;

Published online 24 September 2018 